\title{
Comparison of the fall rate and structure of recent T-7 XBT manufactured by Sippican and TSK
}

\author{
S. Kizu ${ }^{1}$, C. Sukigara ${ }^{1, *}$, and K. Hanawa ${ }^{1}$ \\ ${ }^{1}$ Physical Oceanography Laboratory, Department of Geophysics, Graduate School of Science, \\ Tohoku University, 6-3 Aza Aoba, Aramaki, Aoba-ku, Sendai 980-8578, Japan \\ *now at: Laboratory of Satellite Biological Oceanography, Hydrospheric Atmospheric, Research Center, \\ Nagoya University, Furo-cho, Chikusa-ku, Nagoya 464-8601, Japan
}

Received: 2 August 2010 - Published in Ocean Sci. Discuss.: 27 October 2010

Revised: 24 March 2011 - Accepted: 25 March 2011 - Published: 7 April 2011

\begin{abstract}
The fall rate of recent T-7 expendable bathythermograph (XBT; $760 \mathrm{~m}$ ) is evaluated based on a series of concurrent measurement with a calibrated Conductivity Temperature Depth profiler (CTD) in the sea east of Japan. An emphasis is placed on comparing the fall rates of T-7 produced by the two present manufacturers, the Lockheed Martin Sippican Inc., and the Tsurumi Seiki Co. Ltd., which have been believed to be identical but had never been compared directly. It is found that the two manufacturers' $\mathrm{T}-7$ fall at rates different by about 3.5\%. The Sippican T-7 falls slower than given by the fall-rate equation (FRE) of Hanawa et al. (1995) by about $2.1 \%$, and the TSK T-7 falls faster by about $1.4 \%$. The fall-rate coefficients estimated based on the sea test by applying the equation of traditional quadratic form, $d(t)=a t-b t^{2}$ where $d$ is depth in meters and $t$ is the time elapsed, in seconds, are $a=6.553\left(\mathrm{~m} \mathrm{~s}^{-1}\right)$ and $b=0.00221\left(\mathrm{~m} \mathrm{~s}^{-2}\right)$ for the LMS T-7, and $a=6.803\left(\mathrm{~m} \mathrm{~s}^{-1}\right)$ and $b=0.00242\left(\mathrm{~m} \mathrm{~s}^{-2}\right)$ for the TSK T-7. By detail examination of the probes, we found that the two companies' T-7 have different total weight and many structural differences. Because the difference in the fall rate is about twice larger than the difference in weight (about 2\%), it is inferred that the structural differences give sizable impact to the difference in their fall rates. Our results clearly show that the recent T-7 of the two companies needs to be discriminated.
\end{abstract}

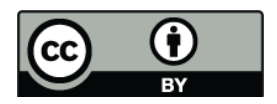

Correspondence to: S. Kizu (kizu@pol.gp.tohoku.ac.jp)

\section{Introduction}

The expendable bathythermograph (XBT) is a ballisticallyshaped probe instrument for measuring temperature profiles of the upper ocean. The probe consists of a metal nose weight with holes that allow water to flow through, and a plastic after-body with three fin stabilizers (Fig. 1). A thermistor is fixed near the front of the nose weight and is linked to an on-board data acquisition system via fine coated wire and a launcher unit. When one deploys the probe from a vessel underway, it freely falls in the water column and measures temperature of water as the resistance of the thermistor, which is recorded by the on-board system normally at a constant time interval. The measurement is terminated at the rated depths, beyond which the manufacturers do not guarantee the quality of measurement, or when the wire runs out and breaks, depending on the acquisition system. A general description of the early system is given by Baker (1981), and a newer review is in Emery and Thomson (2004).

The XBT was developed in the early 1960s to enable quick profiling of water temperature from a fast-moving vessel. Among several institutions and companies, the Sippican Corporation, USA, the antecedent of the present Lockheed Martin Sippican (LMS; hereafter Sippican, except when the present company is particularly referred), won a competition to supply its probes (Demeo, 1969; Francis and Campbell, 1965) to the US Navy (Little, 1965; Shenoi, 1976; Anderson, 1980; Hannon, 2000). The XBT soon became widespread also in the oceanographic community and greatly helped ocean thermal observation network which largely depended on volunteer ships (e.g., White and Bernstein, 1979; Sprintall and Meyers, 1991; McPhaden et al., 1998; Smith et

Published by Copernicus Publications on behalf of the European Geosciences Union. 


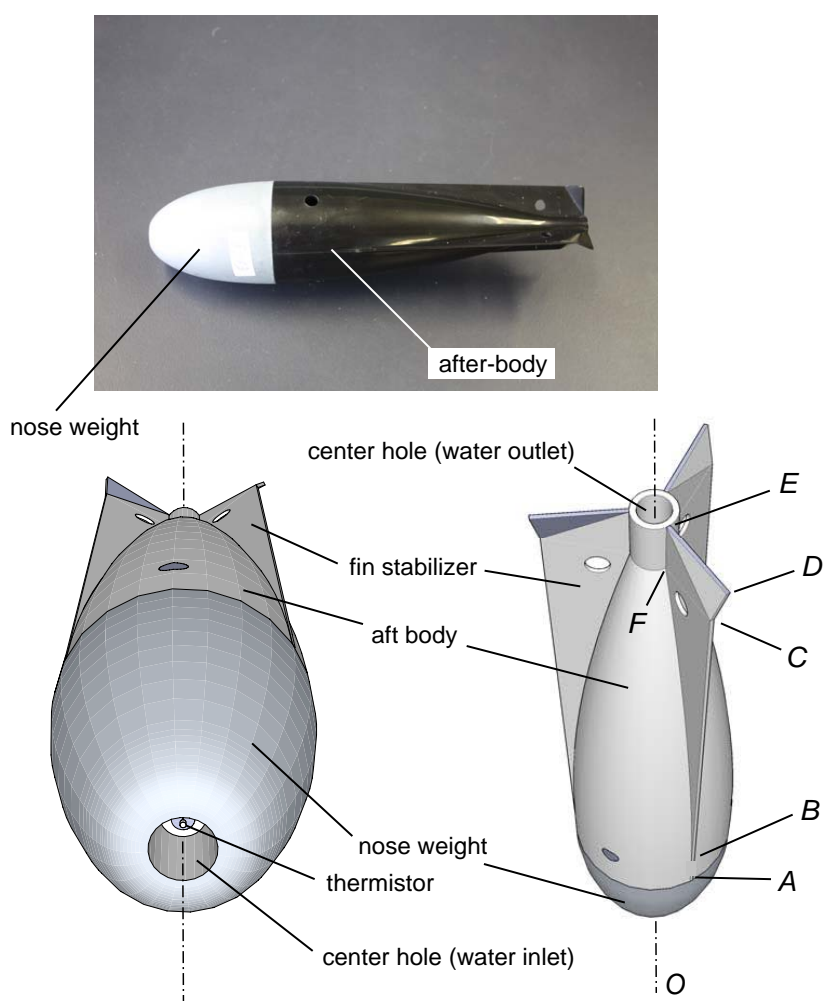

Fig. 1. A side-view photo (top) and sketches of the T-7. Lower left is the front view and lower right is the rear view. The italic alphabets depict the parts of which length is measured and given in Table 2.

al., 1999). Many observational data sets which are presently available owe numerous upper ocean temperature profiles to this easy-handling device (e.g., Boyer et al., 2009). The Tsurumi Seiki, Co. Ltd. (hereafter TSK), Japan, started to manufacture and supply its XBT probes in Japan since the early 1970s under a license agreement with the Sippican (TSK, personal communication, 2009). The TSK's probes have been mostly used by Japanese institutions, and some are exported to other Asian countries. Plessey Marine, UK, had also been a licensed manufacturer and supplier of the Sippican XBT in Europe for some period in the 1970s, but not for now (LMS, personal communication, 2008). As of April 2010, the LMS and the TSK are the only two acknowledged manufacturers, which supply multiple types of XBT for different profiling-ranges and ship speeds to users in their individual sales territories. The present sales territories of the two companies are given in Appendix A. In recent years, some XBT-like probes have been produced by Indian and Chinese manufacturers (F. Reseghetti, personal communication, 2010), but their details are not known.

The T-7 $(760 \mathrm{~m})$ is the most popularly-used type of XBT. It has been manufactured by both the Sippican and the TSK. The former company has also been supplying the T-4, the T-6 and the Deep Blue, all of which were designed to have identical outer shape and the probe weight in water as the T-7.
Similarly, the latter has been manufacturing and supplying the T-6 and a sub-type of the T-7 for faster platforms, by itself. The start of manufacture by the TSK was July 1972 for the T-6 and April 1978 for the T-7. Note that there are other types which have different fall-rates and not discussed here.

Because the XBT carries no pressure sensor, the depth of each temperature sampling is calculated based on the time elapsed since the probe hits the water surface by using a fallrate equation, usually of a quadratic form:

$d(t)=a t-b t^{2}$,

where $d(t)$ is depth in meters at the time elapsed, $t$, in seconds. The equation contains two constant coefficients, $a$ $\left(\mathrm{m} \mathrm{s}^{-1}\right)$ and $b\left(\mathrm{~m} \mathrm{~s}^{-2}\right)$, that are empirically determined for each type of probe (the units are omitted hereafter). The depth accuracy of the XBT is claimed to be $\pm 2 \%$, or $\pm 5 \mathrm{~m}$ near the surface, by the manufacturers. Temperature accuracy is claimed to be $\pm 0.2{ }^{\circ} \mathrm{C}$, according to the product catalogues available from the manufacturers' websites (see http:// www.sippican.com/ for the LMS and http://www.tsk-jp.com/ for the TSK).

The fall rate of the XBT has been assessed by numerous studies in the past. In particular, that of the T-7 was most frequently reviewed because of their popularity (Flierl and Robinson, 1977; Federov et al., 1978; Seaver and Kuleshov, 1982; Heinmiller et al., 1983; Green, 1984; Hanawa and Yoritaka, 1987; Roemmich and Cornuelle, 1987; Wright and Szabados, 1989; Singer, 1990; Hanawa and Yoshikawa, 1991; Biggs, 1992; Hallock and Teague, 1992; Hanawa and Yasuda, 1992; Narayan and Lilly, 1993; Thadathil et al., 1998, 2002; Reseghetti et al., 2007). Most studies prior to the mid-1990s concluded that the original fall-rate coefficients by the Sippican ( $a=6.472$ and $b=0.00216)$ had systematic bias that caused underestimation of depth.

Therefore, Task Team on Quality Control of Automated System (TT/QCAS) made detail analysis of their fall rate (Hanawa et al., 1995; hereafter H95) by collecting a series of sea tests of the T-7 and its relatives in various parts of the world ocean. H95 concluded that the T-4, the T-6, the T-7, and the Deep Blue manufactured by the two companies had virtually identical fall rate. Then the international community of oceanography agreed to use the coefficients proposed by H95, $a=6.691$ and $b=0.00225$, commonly for those six models (Hanawa et al., 1994; recall that the T-6 and the T-7 are manufactured by both the companies). The coefficients by H95 were supported by later studies (e.g., Ridgway, 1994; Thadathil et al., 1998) and became default in the manufacturers' data acquisition system.

However, recent analyses of historical ocean temperature archives demonstrated that the time series of upper ocean heat content was likely contaminated by serious instrumental biases (Gouretski and Koltermann, 2007; Gouretski, 2008; Wijffels et al., 2008; Willis et al., 2009; Carton and Santorelli, 2008; Ishii and Kimoto, 2009; Gouretski 
and Reseghetti, 2010). One of their major concerns was a "warm bias" possibly caused by inaccuracies in the fall rate of the XBT, and most of them concluded that the depth given by the H95's FRE was too deep. For example, Wijffels et al. (2008; hereafter W08) showed that the magnitude of the mean depth error was greater than $3 \%$ at $800 \mathrm{~m}$ depth and $5 \%$ at $400 \mathrm{~m}$ depth for some periods, with considerable variation according to the probe types and years. The errors are in excess of the manufacturers' depth accuracy claim of $2 \%$, if true. They also suggested that the coefficients given by $\mathrm{H} 95$ were valid for the years when probes for H95 were used, but not for the periods before and after that. Different authors suggested different size of the bias and its tendency. Possible depth bias in H95's FRE was also suggested by comparison of nearby XBT and CTD profiles made in the last decade (Reverdin et al., 2009; and a series of cruise reports published by the US Naval Postgraduate School at http://www.weather.nps.navy.mil/ psguest/OC3570/) and by comparison with bathymetry data (Good, 2011).

The fall-rate bias of this magnitude could eliminate "warm 1970s" that have been believed to be real (e.g. Bindoff et al., 2007), and it would also give a very different view of recent global ocean warming (Gouretski and Kolterman, 2007; Wijffels et al., 2008). Therefore, the XBT Fall Rate Workshop was held at NOAA/AOML (the National Oceanographic and Atmospheric Administration/Atlantic Oceanographic and Meteorological Laboratory) in March 2008 to argue this problem again. The web site of the workshop (http://www.aoml.noaa.gov/phod/goos/meetings/2008/ XBT/index.php) includes the results of those recent timeseries analyses plus an extensive list of literature related to this issue. During the reviewing process of the present article, XBT Bias and Fall-Rate Workshop was held in Hamburg in August 2010 for following up more recent research activities.

A problem of those recent studies was that they were mostly based on grid-wise analyses of relatively coarse spatio-temporal resolution rather than concurrent side-byside comparison between instruments. Another problem is that they were purely statistical, and they generally ignored when and how the XBT actually changed. For instance, some of these studies distinguished the Deep Blue and the T-7 manufactured by the Sippican to discuss their biases, but the only difference between the two types is in the length of canister wire, which does not affect the fall-rate. The same applies to the T-4 and the T- 6 made by the Sippican.

Another important point is that there were no studies that directly compared the two companies' T-7 and its relatives at sea. Some of the previous sea tests were made by using Sippican's probes, and the others by TSK's probes. H95 used data taken by each of them, but even they did not compare them side-by-side. This is because the two companies have separate sales territories, and also because people believed that the two companies' products were identical.
Strictly speaking, it was known that the Sippican XBT and the TSK XBT had (and still have) different types of wire and that this makes difference in the weight of probe wire. It was also known that the inside of the nose weight of TSK XBT have been hollowed differently in order to compensate this. Similar adjustment of probe weight has been made by the individual manufacturers between the probes for mediumrange profiling (the T-7 and the Deep Blue) and those for short-range (the T-4 and the T-6). Users considered that this adjustment of weight worked perfectly. Therefore, the XBT made by the TSK was believed to have the same fall rates as the Sippican XBT of the same model name, and we also expected similar identity of fall-rate between the short-range XBT and the medium-range XBT. However, there were no studies that measured their weight, dimensions and shape to assess if they should really have had an identical fall rate. It should also be noted that all parts except the thermistor, which has been exported by the Sippican to the TSK, have been purchased or manufactured independently by the individual companies. Those parts have never been compared directly in the previous studies about the fall-rate problem.

The primary purpose of the present article is to evaluate and directly compare the fall rates of recent T-7 manufactured by the two present manufacturers, on the basis of a series of side-by-side comparisons to a calibrated CTD profiler at sea. Obviously, the history of the fall-rate will never be clarified by our analysis alone. Yet, we believe that frequent side-by-side sea tests and detail inspection of the probes are essential for monitoring the possible change of fall-rate from year to year. We hope that our results will be one of those.

The method and the results of our sea test are described in Sect. 2. The results of our detail examination of the two companies' T-7 are presented in Sect. 3. Discussion and concluding remarks are given in Sects. 4 and 5, respectively.

\section{The sea test}

\subsection{Pre-cruise probe check}

A series of co-located and concurrent measurements by a routinely-calibrated CTD profiler (the Sea-Bird Electronics SBE-9) and the T-7 manufactured by the LMS and the TSK was conducted during 4 through 8 May 2008 off NorthEastern Japan as part of the KY0805 cruise by R/V Kaiyo Maru of the Japan Fisheries Agency, basically following the standard procedures by Sy and Wright (2000). The locations of the measurements are shown in Fig. 2.

Two dozens of the T-7 were supplied for the test by each of the two manufacturers. The serial numbers of the Sippican T-7, which were manufactured on 10 March 2008, are from 1083882 to 1083905 . Those of the TSK T-7, which were manufactured in November 2006, are from 066277 to 066288 and from 066313 to 066324 . 


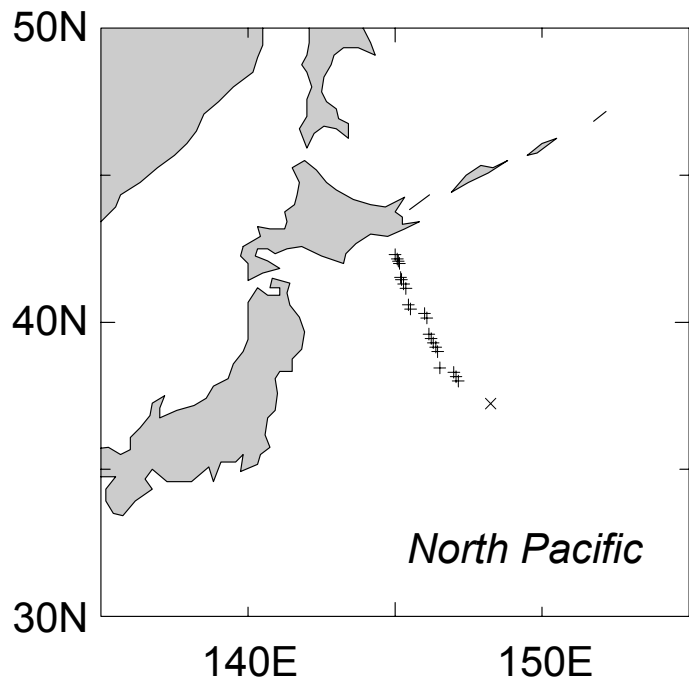

Fig. 2. Locations of our sea tests. The cross indicates the position of the 22rd point. See text for detail.

The weight of all T-7 probes was measured in air prior to the cruise. Also measured are the total length of probe, the length and the maximum diameter of the nose weight, and the position of the center of gravity in air. Their statistical summary is given in Table 1. The linear density of wire, also presented on the table, is calculated based on our measurement of weight of $30 \mathrm{~m}$-long canister wire collected from each probe after the cruise.

It was found that the total weight of one TSK T-7 in air was greater by about $12 \mathrm{~g}$ (about $1.6 \%$ of total weight) on average than that of one Sippican T-7 in our sample. The probe-to-probe variance in weight of the Sippican T-7 in air is five times larger than that of the TSK T-7, and this is consistent with the industrial tolerance for the probe weight in air, which is specified by each company: $5 \mathrm{~g}$ for the Sippican XBT and $1 \mathrm{~g}$ for the TSK XBT. Based on this, two Sippican T-7 (the lightest and the heaviest one) and one TSK T-7 were kept for later detail examination (see Sect. 3). The rest, namely 22 Sippican T-7 and 23 TSK T-7, were tested in the sea according to the procedure described in the next subsection. The probe-to-probe difference of the total weight is also shown in Fig. 3. The results of the rest of the measurement will be discussed in Sect. 3 .

\subsection{Sea test procedure}

Temperature profiles were obtained by the T- 7 at 22 CTD stations when the vessel was under operation for CTD measurement (i.e. almost stationary). The temperature profiles obtained by the CTD profiler are shown in Fig. 4 .

A single TSK handheld launcher and a single TSK MK130 System were used throughout the measurement. At each CTD station, a first T-7 was released when the CTD was at about $10 \mathrm{~m}$ depth on its sinking path. After the first one fin- ished, a second T-7 was set and launched. At 21 of total 22 CTD stations, a Sippican T-7 was released first and a TSK T7 was released second. Only at the 22nd CTD station where we tested two TSK T-7 and one Sippican T-7, one TSK T-7 was released first, a Sippican T-7 second, and a second TSK T-7 was released last. Typically it takes 2 min to complete one profile by a T-7. The time difference between individual profiles by T-7 and a CTD measurement to be compared therefore varied from several to about $10 \mathrm{~min}$, depending on depth. The ship drift during one set of measurement was smaller than $700 \mathrm{~m}$.

All probes used were stored in a laboratory of the vessel at room temperature before each measurement. The individual TSK T-7 was enclosed in a vinyl envelope with a desiccant package, as usually done by the company upon shipping. We broke the envelope shortly (within several minutes) before individual measurement. The Sippican T-7 was supplied by using similar cardboard boxes but without such damp-proof enclosure.

The probes were carefully launched from a lee side of the lower deck at several meters above the water surface though precise launching height varied from case to case according to the sea state. There was no apparent wire contact with ship hull, but nine profiles (i.e. $41 \%$ ) obtained by the Sippican T7 were at least partially erroneous perhaps due to break of the wire insulation occurred in seawater during the measurement. We asked the LMS if there were any problems in the manufacture of those particular probes, but the company denied that possibility. Four of those nine are discarded from the determination of fall rate because the error-free part of the profiles was too short. The rest (i.e. five profiles) of them are utilized after removing the erroneous parts that were mostly found at the deepest levels. All TSK probes worked without such electrical leakage problem.

The sampling rate of our XBT measurement is $20 \mathrm{~Hz}$. This corresponds to a vertical resolution of about $33 \mathrm{~cm}$ for the T-7, according to H95's FRE. The vertical resolution of the CTD data is one decibar. The CTD profiler used in this investigation has routinely been calibrated, and we assume that the nominal accuracy $\left(0.003 \mathrm{mmho} \mathrm{cm}^{-1}, 0.001{ }^{\circ} \mathrm{C}\right.$ and $0.015 \%$ for conductivity, temperature and pressure, respectively) was maintained throughout the investigation.

\subsection{Estimation of depth error}

The method of Hanawa and Yasuda (1992) is used in order to estimate the depth error of individual T-7 profiles. We assume that the CTD profiles are the truth. The method of analysis is briefly described in the following.

First, the individual temperature profiles are processed with a 7-point median filter to remove spikes. Secondly, they are interpolated at one meter interval, and thirdly smoothed with a 41-point Hanning filter. The choice of (especially the second) filter is rather arbitrary, and the decision is made according to a compromise between advantage (i.e. good 
Table 1. The results of pre-cruise probe measurement. From the left to right, total length of probe, maximum diameter of nose weight, length of nose weight, the position of the center of gravity in air $\left(P_{\mathrm{CG}}\right)$, and total weight of probe in air $W_{\mathrm{fw}}$, air are given. The minimum, maximum, and mean of the 24 T-7 probes are presented for each manufacturer. Weights are given in the unit of grams, and lengths are in mm. $\rho_{\text {wire }}$ is the linear density of wire in $\mathrm{g} \mathrm{m}^{-1}$. See text for more detail.

\begin{tabular}{llrrrrrr}
\hline Manufacturer & & $\begin{array}{r}\text { Total } \\
\text { length }\end{array}$ & $\begin{array}{r}\text { Nose } \\
\text { diameter }\end{array}$ & $\begin{array}{r}\text { Nose } \\
\text { length }\end{array}$ & $P_{\mathrm{CG}}$ & $W_{\mathrm{fw}, \text { air }}$ & $\rho_{\text {wire }}$ \\
\hline \multirow{3}{*}{ Sippican } & min & 215.4 & 50.8 & 60.3 & 54.2 & 725.8 & 0.118 \\
& max & 216.0 & 50.8 & 60.8 & 54.7 & 732.4 & 0.121 \\
& mean & 215.9 & 50.8 & 60.5 & 54.5 & 728.9 & 0.121 \\
& max-min & 0.6 & 0.0 & 0.5 & 0.5 & 6.6 & 0.003 \\
TSK & min & 216.1 & 51.0 & 61.3 & 56.0 & 739.8 & 0.131 \\
& max & 216.3 & 51.0 & 61.5 & 56.4 & 741.1 & 0.132 \\
\multirow{3}{*}{ Mean difference } & mean & 216.2 & 51.0 & 61.4 & 56.2 & 740.5 & 0.132 \\
& max-min & 0.2 & 0.0 & 0.2 & 0.4 & 1.3 & 0.002 \\
& TSK-SIP & 0.3 & 0.2 & 0.9 & 1.7 & 11.6 & 0.011 \\
\hline
\end{tabular}

(a) Sippican T-7
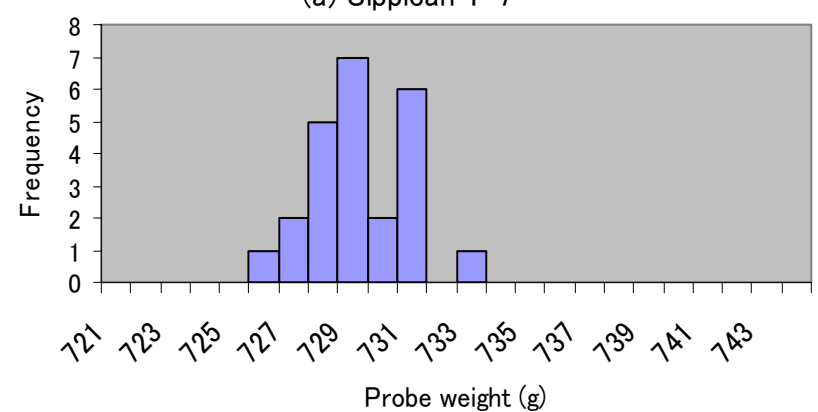

(b) TSK T-7

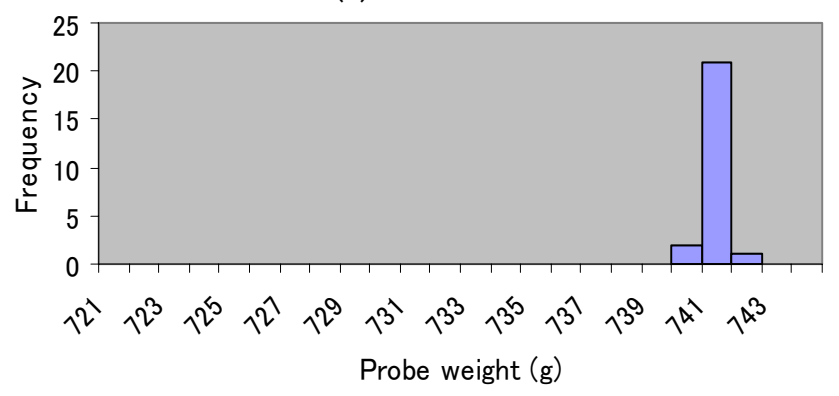

Fig. 3. Histogram of the total probe weight in air. (a) The Sippican T-7. (b) The TSK T-7.

vertical resolution) and deficit (i.e. higher noise) of retaining high wave number structures in the profiles. The pressure-todepth conversion is made for the CTD profiles by using an equation $d=0.993 \cdot p$, as done by H95, prior to the vertical interpolation. Fourthly, the vertical gradient of temperature is calculated for a total depth range of the individual T-7 and CTD profiles. Finally, the depth error is estimated by search-

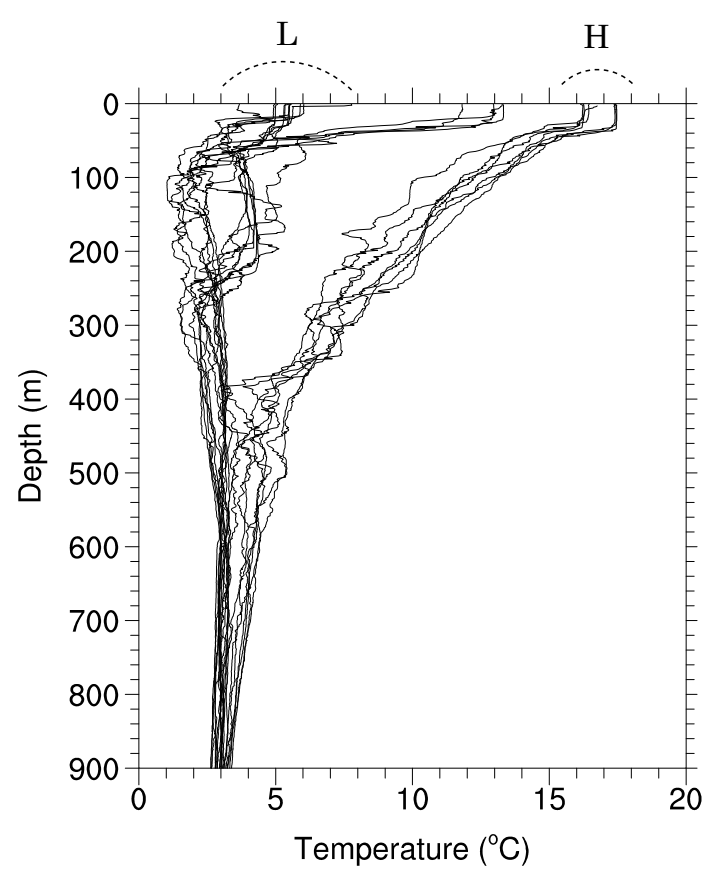

Fig. 4. Temperature profiles by CTD. Subgroup "H" and "L" are characterized by high and low surface temperatures, respectively. Note that four profiles characterized by intermediate surface temperature $\left(11 \leq \mathrm{SST} \leq 14{ }^{\circ} \mathrm{C}\right)$ are not included in either subgroups.

ing for a depth offset which gives the smallest difference between the profile of temperature gradient by the T-7 and that by corresponding CTD measurement. These procedures are repeated for all T-7-CTD profile pairs obtained from our sea test. See H95 or Hanawa and Yasuda (1992) for further details of the method. 


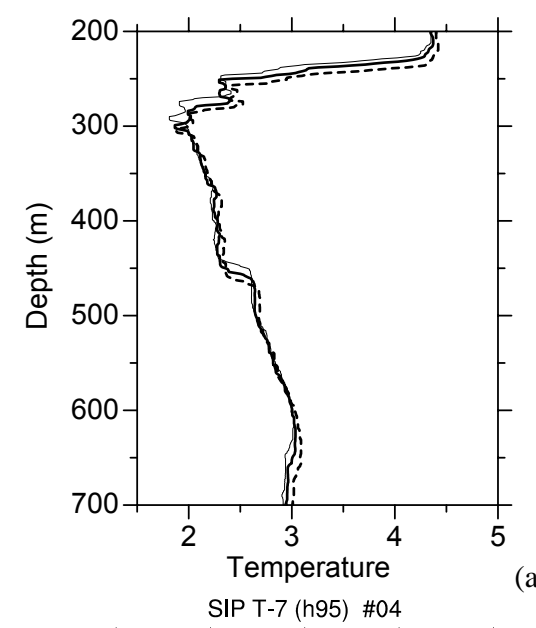

(a)

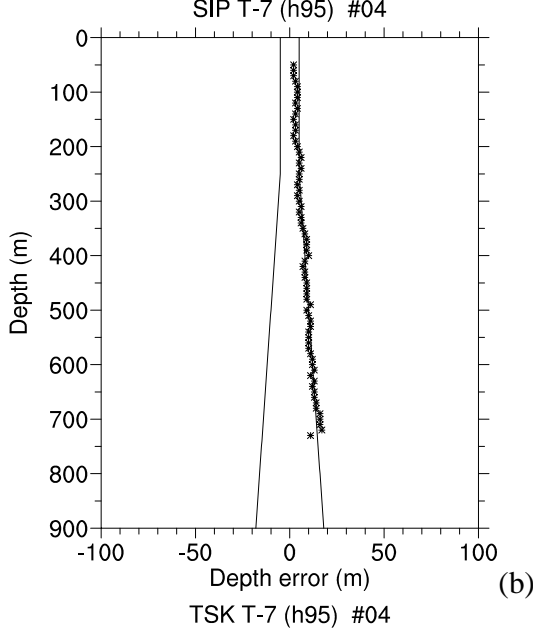

(b)

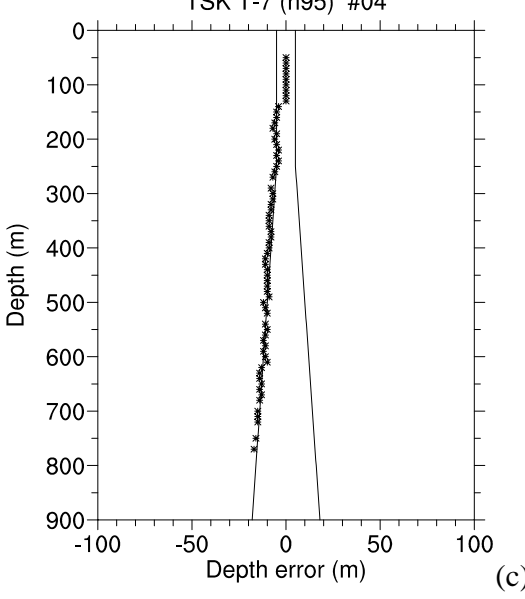

Fig. 5. A typical example for showing the data processing. (a) Vertical temperature profiles by CTD (thick solid line), the Sippican T-7 (dashed line) and the TSK T-7 (thin solid line). (b) The depth error of H95's fall-rate coefficients estimated at various depth levels for the Sippican T-7 whose profile is shown in (a). (c) Same as (b) but for the TSK T-7. Solid lines in (b) and (c) indicate the manufacturers' claim for depth accuracy. Note that only limited depth range is shown in (a) for clarity.

\subsection{Result}

An example is presented in Fig. 5 to show how the present method detects depth error of an XBT profile. Figure 5a shows raw (i.e. unfiltered) temperature profiles obtained at one of the stations by the CTD profiler and the T-7 manufactured by the two companies. Obviously, the depth of the profile obtained by the Sippican T-7 (S/N 1083895) is positively biased, and the T-7 ( $\mathrm{S} / \mathrm{N} 066319)$ is negatively biased. The positive depth error indicates that the true fall rate of the probe is slower than the H95, and vice versa. Similar tendency is observed in all available pairs of profiles (not shown here).

Also, in this case, a positive temperature offset is found in the profile taken by the Sippican T-7. The offset varies from 0.04 through $0.07^{\circ} \mathrm{C}$ in the depth range shown. In contrast, a negative temperature offset of about $0.03{ }^{\circ} \mathrm{C}$ or less is found in the same depth range of the profile taken by the TSK T-7. However, we do not consider these are typical temperature offsets of each manufacturer's T-7 because those values differ and sometimes even change signs in the case of the other pairs. We rather conclude that we could not identify significant temperature bias with this small sample.

Figure $5 \mathrm{~b}$ and $\mathrm{c}$ shows the error of depth at various CTD depth levels, which is detected by the present method for each of the two T-7 profiles shown in Fig. 5a. As suggested by the temperature profiles, the depths of the profile obtained by the Sippican T-7 and those by the TSK T-7 are clearly biased in opposite directions; the former shows positive depth error and the latter shows negative depth error. The size of the depth error is about $2 \%$ (with different signs) for these two probes.

Figure 6 shows a histogram of the depth error obtained at various depth levels from all of the available pairs of profiles. The depth calculated for the Sippican T-7 is biased in positive direction except near the surface where tendency is not clear (Fig. 6a). The size of the bias is nearly equal to or slightly larger than $2 \%$, the manufacturers' specification of the depth accuracy. In contrast, the depth of the TSK T-7 is systematically biased in negative direction (Fig. 6b) though the magnitude of the error is mostly smaller than $2 \%$. These results again suggest that the true fall rate of the present Sippican T-7 is slower than given by H95's fall-rate equation, and that of the present TSK T-7 is faster.

Similar results were reported by Derrick Snowden and his colleagues at the Miami XBT Fall-rate Meeting (Snowden et al., 2008). Also, Reverdin et al. (2009) estimated a fall-rate bias of almost the same size (1.7\%) for the Sippican T-7 and Deep Blue. So we note that those fall-rate bias should be characteristic of the recent Sippican probes.

Next, the best-fit fall-rate coefficients are determined for the individual T-7 by the least-square method and summarized in Fig. 7. The results clearly demonstrate that the T-7 manufactured by the two companies have systematically different fall rates. The difference between the two groups is 


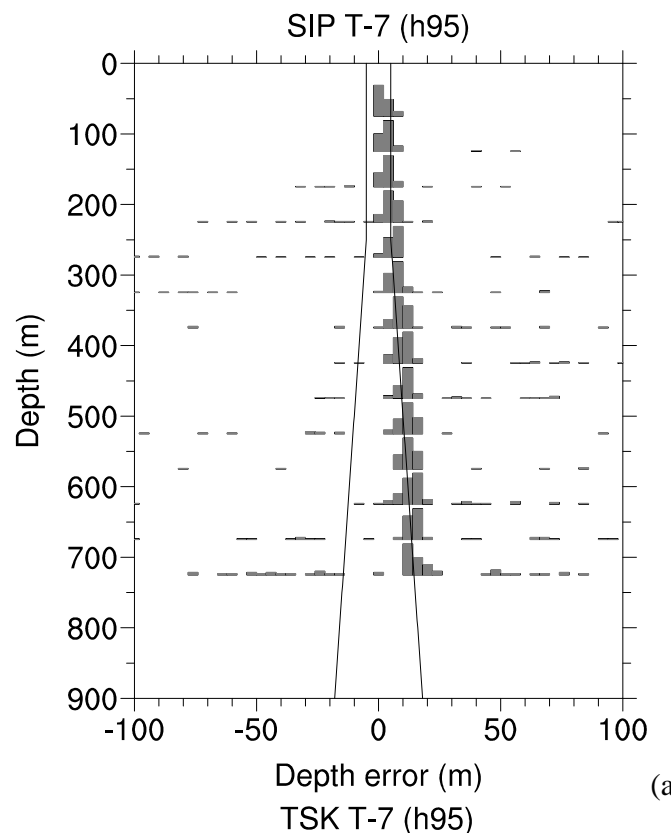

(a)

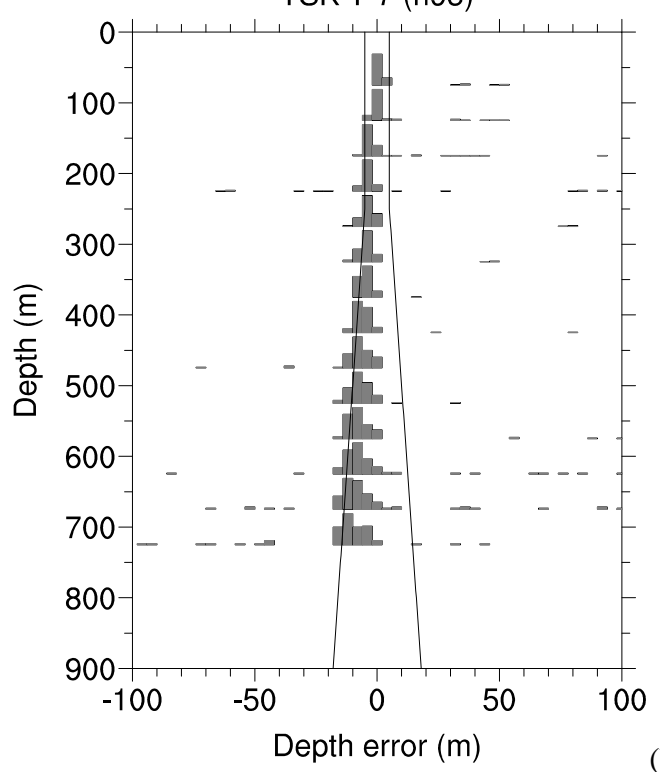

(b)

Fig. 6. The depth error of the H95's fall-rate coefficients at various depth levels. (a) The Sippican T-7 (18 probes). (b) The TSK T-7 (23 probes). The vertical axis is the depth by CTD, and the horizontal axis is the error of depth. Vertical bars, scaled arbitrarily, indicate relative frequency of the occurrence of the error in each depth bin $(50 \mathrm{~m})$. Solid lines show the manufacturer's claim for depth accuracy.

almost $3.5 \%$, and the coefficients by $\mathrm{H} 95$ are just located between them. These results are consistent with the aforementioned profile-to-profile comparison (Figs. 5 and 6).

Interestingly, the fall-rate coefficients show some dependency on the water temperature. The coefficients $a$ and $b$ obtained from profiles with higher surface temperature (marked by " $\mathrm{H}$ " in Fig. 4) are generally larger than those from profiles

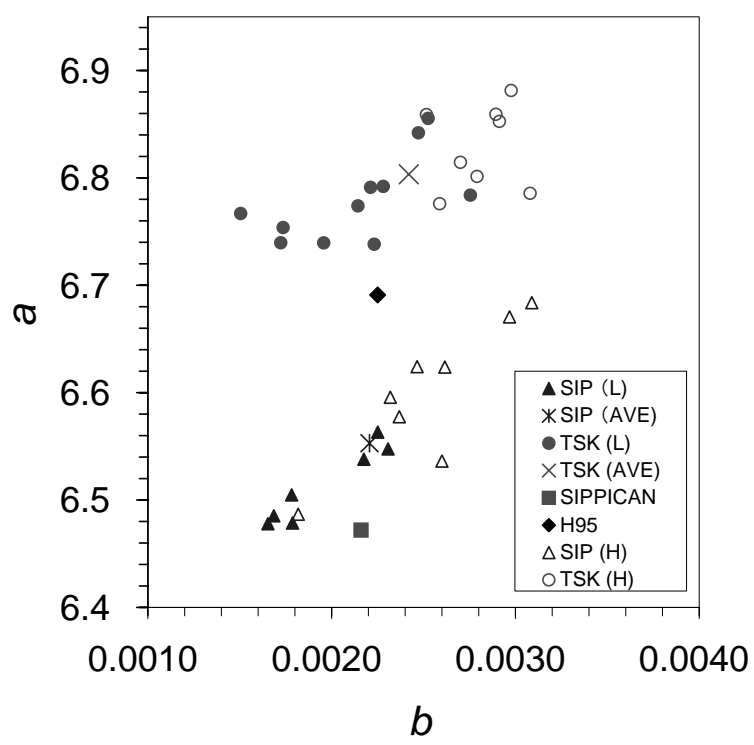

Fig. 7. The fall-rate coefficients estimated for the individual T-7 profiles. The horizontal axis is $b$ coefficient and the vertical axis is $a$ coefficient. Closed and open circles indicate those for low and high temperature subgroups (see Fig. 4), respectively, by the TSK T-7. Closed and open triangles indicate those for low and high temperature subgroups, respectively, by the Sippican T-7. The asterisk and the cross depict means for the Sippican and the TSK T-7, respectively. The closed square depicts the original coefficients by the Sippican, and the closed diamond indicates those by H95.

with lower surface temperature (marked by "L" in Fig. 4). In other words, the T-7 in " $\mathrm{H}$ " subgroup had faster initial fall rate but also experienced quicker deceleration. This tendency is commonly observed for the T-7 made by each of the companies, though the sample for the Sippican T-7 is smaller than the TSK T-7 because of the loss of profiles due to the leakage problem. The profiles in " $\mathrm{H}$ " subgroup are characterized by higher surface temperature and higher vertical gradient of temperature than those in "L" subgroup (Fig. 4). Therefore, it is inferred that the fall rate of the T-7 is faster in warmer (i.e. less viscous) water, but that the faster initial fall rate is mostly cancelled by larger $b$ coefficient that is likely caused by greater decrease of temperature (i.e. increase of viscosity) in the middle to lower part of the profiling range. It is also suggested that the probes are likely to feel the water temperature of relatively thin layer they go through.

Figure 8 shows comparison between the fall rates at the surface $(t=0)$ and those at $t=110$ (i.e. $d \geq 700 \mathrm{~m}$ ) estimated for individual samples by the first derivative of Eq. (1), namely,

$v(t) \equiv a-b t$.

It is confirmed that the systematic difference in initial fall rates (i.e. horizontal axis) between the two temperature subgroups is reduced or mostly lost in the deepest part of the profiling range (i.e. vertical axis). Because the difference 


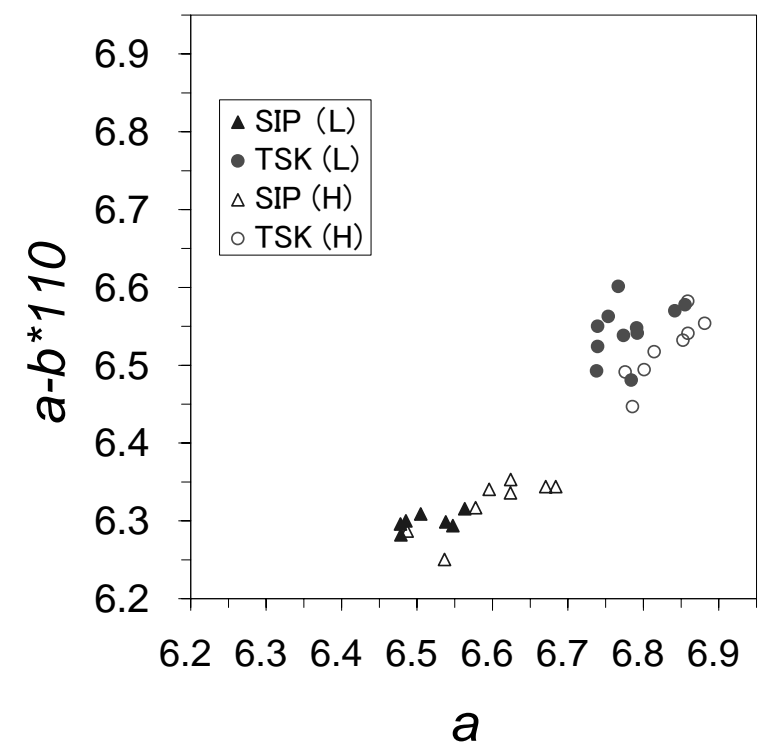

Fig. 8. Comparison between the fall rate at the surface ( $t=0$; horizontal) and that at depth ( $t=110$; vertical) according to the estimated fall-rate equations for individual probes. Symbols are the same as in Fig. 7 except that the averages and the literature values are not shown for clarity.

in temperature between the two subgroups in lower layer is at least several times smaller than that near the surface (see Fig. 4), the results are thought to be an evidence of the dependency of fall rate on water temperature (i.e. viscosity), which was often suggested by earlier studies (e.g., Sippican, 1976; Barnett and Bernstein, 1980; Green, 1984) but had scarcely been proven in real sea. The present results are qualitatively coincident with Thadathil et al. (2002) which showed that the fall rate of the Sippican T-7 was slower than given by H95's coefficients in water of extremely low temperature. The dependency of fall rate on water temperature was also shown for the T-5 manufactured by both the companies (Kizu et al., 2005a), and the XCTD-1 and the XCTD-2 (Kizu et al., 2008). Similar small temperature-dependency of the coefficients was also partially obtained by H95 (see their Figs. 8 and 9) though they eventually concluded that there was no significant global relationship between the water temperature and the fall rate.

We also tried to investigate how the fall rates depends on the weight of the probes. But we could not separate the weight-dependency from the temperature-dependency of the fall rates because we tended to drop lighter Sippican probes at the sites of colder seas by innocence (not shown). We could only obtain the data of weights after the cruise. We will obviously need to design better-controlled sea tests to separate the two factors.

When the possible temperature-dependency is neglected, the mean and the standard deviation of the fall-rate coefficients obtained in the present study are $a=6.553 \pm 0.064$
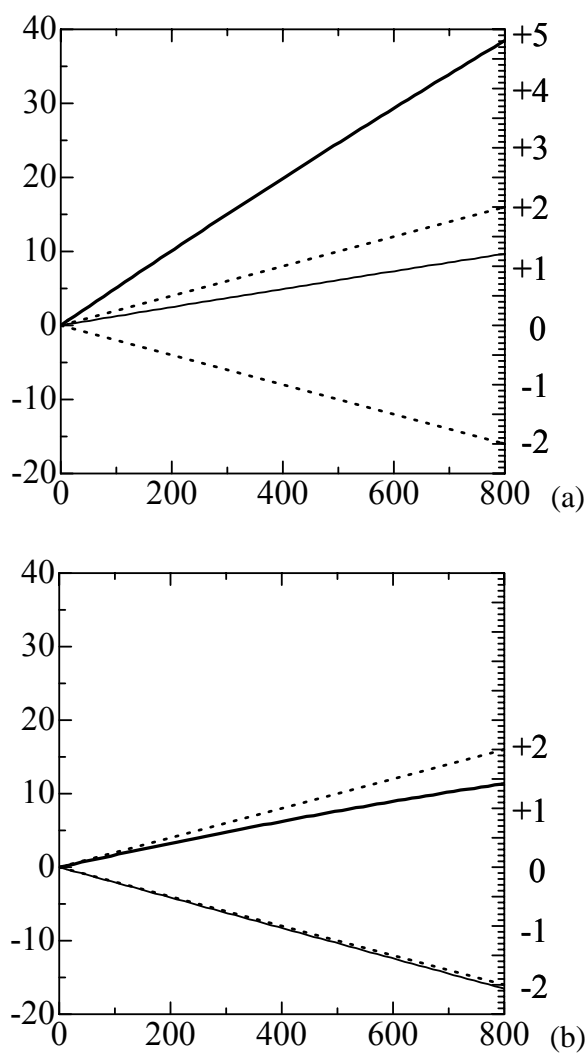

Fig. 9. (a) The relative depth difference between each of the present fall-rate equations and the original equation by the Sippican, as a function of depth given by the latter. (b) Same as (a) but between each of the present fall-rate equations and H95. The unit for the horizontal axes and the left vertical axes is $\mathrm{m}$. The right vertical axes show relative deviation from the depth given by each literature equation (the unit is percent). Thin solid lines indicate the fall-rate equation estimated in the present study for the tested Sippican T-7, and thick sold lines indicate that for the tested TSK T-7. The dotted lines indicate the manufacturers' claim for depth accuracy $(2 \%)$.

and $b=0.00221 \pm 0.00043$ for the LMS T-7 $(N=18)$, and $a=6.803 \pm 0.052$ and $b=0.00242 \pm 0.00044$ for the TSK T$7(N=23)$, where $N$ is the number of probes used for the statistics.

The relative differences between depth by each of the present two fall-rate equations and that by each of the original manufacturers' equation and H95's equation are shown in Fig. 9. The present equation for the Sippican T-7 gives $1.2 \%$ greater depth than the original equation by the manufactures and $2.1 \%$ smaller depth than $\mathrm{H} 95$ at the greatest depth in the graph. The present equation for the TSK T-7 gives $4.8 \%$ greater depth than the original equation and $1.4 \%$ greater depth than $\mathrm{H} 95$ at the same depth. The difference between the present equations and $\mathrm{H} 95$ are almost within the manufacturers' claim for depth error (i.e. $2 \%$; shown by dotted lines). 
Table 2. Weights and dimensions of various parts of the Sippican T-7 and the TSK T-7, and the difference between them. $W_{\mathrm{fw}}$ : $:$ weight of a probe with full wire in air; $W_{\mathrm{fw}, \mathrm{w}(1)}$ : weight of a probe with full wire in water before deaeration; $W_{\mathrm{fw}, \mathrm{w}(2)}$ : weight of a probe with full wire in water after deaeration; $W_{\mathrm{nw}, \mathrm{w}}$ : weight of a probe without wire in water; $W_{\text {nose,w }}$ : weight of a nose weight in water; $\phi_{\text {nose hole }}$ : diameter of central hole in the nose weight; $D_{\text {fin(1) }}$ : thickness of the tail fin at its frontal end; $D_{\text {fin(2) }}$ : thickness of the tail fin at its folded point. The columns with two consecutive capital alphabets show the length of sides: e.g. CE means the length of side between point $\mathrm{C}$ and point $\mathrm{E}$, and $\mathrm{OC}$ means the distance between point $\mathrm{C}$ and the central axis (see Fig. 1). The unit for weights is grams, and that for lengths is $\mathrm{mm}$. See text for more detail.

\begin{tabular}{|c|c|c|c|c|c|c|c|c|c|c|c|c|c|c|}
\hline Manufacturer & $\mathrm{S} / \mathrm{N}$ & $W_{\mathrm{fw}, \mathrm{a}}$ & $W_{\mathrm{fw}, \mathrm{w}(1)}$ & $W_{\mathrm{fw}, \mathrm{w}(2)}$ & $W_{\mathrm{nw}, \mathrm{w}}$ & $W_{\text {nose, } \mathrm{w}}$ & $\phi_{\text {nose hole }}$ & $D_{\text {fin }(1)}$ & $D_{\text {fin(2) }}$ & OC & OD & $\mathrm{CE}$ & $\mathrm{CD}$ & $\mathrm{DE}$ \\
\hline \multirow{3}{*}{ Sippican } & 1083890 & 732.3 & 563.8 & 566.6 & 487.3 & 485.1 & 11.05 & 3.55 & 1.25 & 15.7 & 18.8 & 17.7 & 11.0 & 14.2 \\
\hline & 1083897 & 725.8 & 559.7 & 561.4 & 485.9 & 484.2 & 11.05 & 3.60 & 1.20 & 15.8 & 18.9 & 17.8 & 11.0 & 14.3 \\
\hline & mean & 729.1 & 561.7 & 564.0 & 486.6 & 484.7 & 11.05 & 3.58 & 1.23 & 15.8 & 18.9 & 17.8 & 11.0 & 14.3 \\
\hline TSK & 066313 & 740.5 & 565.0 & 576.5 & 487.2 & 485.1 & 10.55 & 2.20 & 0.85 & 15.4 & 20.0 & 17.1 & 9.9 & 15.5 \\
\hline \multicolumn{2}{|c|}{ Difference (TSK-SIPmean) } & 11.5 & 3.2 & 12.5 & 0.6 & 0.5 & -0.50 & -1.38 & -0.38 & -0.4 & 1.2 & -0.6 & -1.1 & 1.3 \\
\hline
\end{tabular}

\section{Probe structure}

Detail examination of the T-7 was made in May 2008 at the TSK Shirakawa Factory and later at the Physical Oceanography Laboratory of Tohoku University. Two Sippican T-7 probes (S/N 1083890 and 1083897) and one TSK T-7 probe (S/N 066313) were used, and the weight and dimensions of their parts were measured by an electronic balance, slide calipers and a vernier height gauge. Also, the wire was collected from the canister spools of all probes used in the sea test, and its linear density was measured.

The measurement of weight was done in air and faucet water. First, the total weight of probe was measured in air, and secondly in water. Next, the probe was deaerated in a pressured water tank so that the small bubbles caught around the probe wire were removed. Then the probe weight was measured in water again. Then the probe wire was unreeled, and the probes were decomposed into parts. Finally, the weight of each part except the wire was measured in air, and then in water. This procedure was repeated for every sample T-7. The results are summarized in Table 2.

Table 2 shows that more than $86 \%$ of the probe weight with full wire in water is due to the metal nose weight, and most of the rest comes from the probe wire. The weights of probe spool and after-body (not shown) are respectively smaller than $2 \mathrm{~g}$ in water. The average weight of the TSK T-7 with full probe wire in air is greater than that of the Sippican T-7 in the same condition by about $12 \mathrm{~g}$. The weight difference between the Sippican T-7 and the TSK T-7 in water is about $3 \mathrm{~g}$ before deaeration, but $13 \mathrm{~g}$ after that. The weight of the Sippican T-7 with full wire in water increased by about $2 \mathrm{~g}$ by deaeration, and that of the TSK T-7 increased by about $12 \mathrm{~g}$. The weights of two manufacturers' T-7 without wire were almost the same in water, and the weights of all parts except the wire in water did not change by deaeration. These results suggest that air bubbles caught by probe wire may cause measurable impact on the probe weight particularly of the TSK XBT. The difference in probe weight in water approached that in air when bubbles were removed. However, more samples are needed to draw more solid conclusion about this bubble effect.

After the submission of this article, Franco Reseghetti presented similar results from his measurements of LMS XBT probes in the Hamburg XBT meeting, which reinforce a leading idea of this paper: the probes manufactured by the LMS and the TSK are different.

The weight differences among nose weights of the three probes are smaller than $1 \mathrm{~g}$, and the differences among volumes of them are smaller than $1 \%$ (not shown here). Although the number of our samples is obviously small, the difference in the mass of nose weight between the two manufacturers' $\mathrm{T}-7$ is thought to be insignificant and within the manufacture tolerance. This fact clearly disagrees with our past understanding that the weight of nose weight is differentiated by the two manufacturers to cancel the difference in the weight of probe wire. Because differences in the weights of the plastic parts are almost negligible in water, the difference in total weights of the two companies' T-7 is originated from the difference in the weight of probe wire. When we divide the difference in the probe weight with full wire (about $12 \mathrm{~g}$ ) by the average difference in linear density of wire (i.e. $0.011 \mathrm{~g} \mathrm{~m}^{-1}$; see Table 1 ), the quotient reasonably agrees with the length of probe wire of the T-7.

Hottel Jr. (1972) described that the Sippican XBT was equipped with wire of gauge number 39 , which is supposed to weigh about 0.113 grams per meter according to the table of standards of the gauge. The LMS claims that no change has been made to the wire itself since its start of manufacture (LMS, personal communication, 2009), and the TSK has been using wire of the same gauge number for its XBT (TSK, personal communication, 2008). These seem to be consistent with our measurement of linear density of the wire, with uncertainty about the weight of materials for the insulation coating.

From these results, it is concluded that the difference of probe weight in water is largely due to the difference in the 
weight of probe wire. It is also likely that the difference in probe weight in water does not exceed the weight difference in air, $12 \mathrm{~g}$, which is $2 \%$ of the total weight of a probe in water.

Also given in Tables 1 and 2 are the diameter of the center hole where the thermistor is fixed, the outer diameter of nose weight, the length of a probe and the nose weight, and the position of the center of gravity in air, and the average thickness and size of the fins. Note that the numbers in Table 1 are the statistics obtained from the 24 probes of T- 7 for each manufacturer and those in Table 2 are obtained from one (for the TSK) or two (for the Sippican) of those.

There are many differences between the Sippican T-7 and the TSK T-7:

1. The diameter of the central hole of the latter is $0.5 \mathrm{~mm}$ $(4.6 \%)$ smaller than that of the former.

2. The length of nose weight, measured from its frontal end to the boundary connected to the after-body, of the latter is $1 \mathrm{~mm}(1.7 \%)$ longer than that of the former. Accordingly, the position of the center of gravity of the latter is located about $2 \mathrm{~mm}$ behind of that of the former (Table 1).

3. The diameter of the nose weight of the latter is $0.2 \mathrm{~mm}$ $(0.4 \%)$ larger than the former.

4. The three fins, which consist of main part that extends radially outward from the after-body (the part enclosed by BCEF in Fig. 1) and angled small tail part (CDE in Fig. 1), of the TSK T-7 are thinner than the Sippican $\mathrm{T}-7$, by $1.4 \mathrm{~mm}$ at their frontal ends (point B in Fig. 1).

5. The length between point $B$ and point A, the boundary between the after-body and the nose weight, of the TSK T-7 is smaller by about $5 \mathrm{~mm}$ than the Sippican T-7.

6. The width of the main part of the fins (i.e. the length between point $\mathrm{C}$ (Fig. 1) and the central tube) of the TSK T-7 is $0.4 \mathrm{~mm}$ smaller than the Sippican T-7. The endmost corners of the three tail fins (point D in Fig. 1) of the TSK T-7 are located $1.2 \mathrm{~mm}$ outward than the Sippican T-7. Consequently, the angled part of the fins extends slightly outward from outer edge of their main part (i.e. the line from B to C) in the TSK T-7, but is located well inside of the line in the Sippican T-7. In addition, the size of the angled tail part of the Sippican T-7 is larger than that of the TSK T-7 by a few percent.

7. The inner volume of the after-body of the Sippican T-7 is larger by about $5 \mathrm{~cm}^{3}(3.5 \%)$ than the TSK T-7.

These structural differences between the two manufacturers' probes are similarly found between the TSK T-5 and the Sippican T-5 that were investigated in Kizu et al. (2005a). Because the T-5 and the T-7 share the same outer design of the nose weight and the rear part of the after-body, it is likely

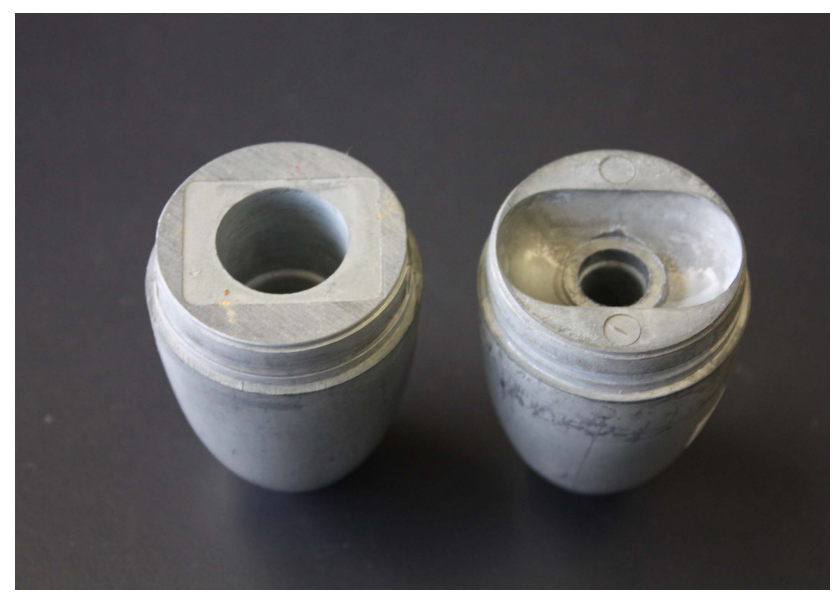

Fig. 10. The inside of the metal nose weight of the TSK T-7 (left) and the Sippican T-7 (right).

that these differences between the manufacturers have been existent at least for a half-decade.

Furthermore, a remarkable difference between the Sippican T-7 and the TSK T-7 is in the inside design of the metal nose weight, as shown in Fig. 10. The TSK T-7 has concentric design, but the Sippican T-7 does not. According to the manufacturer's information, the Sippican Deep Blue has the same inside design as its T-7 but its T-4, T-5, T-6, and T-10 commonly have a concentric design (LMS, personal communication, 2009), and all TSK XBT have concentric weight design (TSK, personal communication, 2009). Both manufacturers also claim that the inner design of the nose weight has never been changed for each probe type.

\section{Discussion}

Figure 8 shows that the difference between the fall rates of the two manufacturers' T-7 was kept almost unchanged from near the surface to the deepest part of the profiles where the probe wire was expired. When we assume that the probes fall by their terminal velocities at each depth in water, this suggests that the difference in the fall rate is significantly caused by factors other than the weight difference, which should vanish when the wire runs out.

A possible factor to explain this is the structural differences. The difference in the size and angles of the tail fins may produce difference in rotational torque to cause different spin motion. The differences in the fins may also cause different wake, possibly in cope with the difference in the thickness of the fins. Different inner design of the nose weight might affect the difference in stability of descent to cause different tendency in wobbling of the probe that were suggested in previous studies (e.g. Green, 1984). However, those are just guesses and it is very difficult to assess if and quantify 
how each of these structural differences contributes to the difference in the overall fall rates.

Reynolds number in the situation where the probe (with diameter $d \approx 5 \mathrm{~cm}$ ) falls at velocity of $6.5 \mathrm{~m} \mathrm{~s}^{-1}$ in water (with dynamic viscosity $v \cong 1.0 \times 10^{-6} \mathrm{~m}^{2} \mathrm{~s}^{-1}$ at $10^{\circ} \mathrm{C}$ ) is about $3 \times 10^{5}$, which means that the flow regime around the falling probe is turbulent, as discussed in Green (1984). The sharp fins should help separation of boundary layer, and water that flows out from the central vent should also help that process. These conditions will not be easily handled even with a sophisticated hydrodynamic model, when we want to estimate the fall rate with accuracy better than a few percent. Nevertheless, there are multiple evidences to expect different fall rates for the two manufacturers' probes with a common model name and also for different types of probe produced by either manufacturer, which have been thought to fall at an identical rate.

The comparison between the fall rate of the Sippican T-7 and that of the TSK T-7 was also made by H95 though they were not based on direct side-by-side comparison. Their conclusion was that the difference was negligible compared to the large variance among data subsets obtained in various sea areas of the world. Our finding obviously disagrees with this. However, it should be noted that structural identity between the probes used in $\mathrm{H} 95$ and those used in the present study is not proven because $\mathrm{H} 95$ did not make any measurement of weight nor structural inspection of the probes.

There are three hypotheses. The first is that there was a systematic difference between the Sippican T-7 and the TSK T-7 already at the time of H95, which failed to detect it. However, the difference between the mean fall rate of the Sippican T-7 and that of the TSK T-7 in our sample is about $3.5 \%$, which could hardly be overlooked in H95. Their Figs. 8 and 10 clearly show that the T-7 manufactured by the two companies at that time had no such systematic difference in the fall rate and that the mean differences between the manufacturers or among the probe types were much smaller. W08 also suggested that there was no sizable bias of fall rate for the period of H95. So, the first hypothesis can almost be dismissed.

The second possibility is that there was no systematic difference between the two companies' T-7 at the time of H95, but there is now. The third is that the disagreement between $\mathrm{H} 95$ and the present results is wholly caused by variance among production lots. Neither of these two possibilities could be eliminated immediately because our sample is small. More frequent sea tests will be needed to conclude whether or not this $3.5 \%$ difference is really systematic. If the second scenario is right, the results by $\mathrm{H} 95$ and those by the present study can be consistent. In addition, it means that at least some conclusions by W08, or studies which similarly suggested time-varying fall rate, are supported. However, in that case, some structural change has to be brought by either or both manufacturers after H95. This obviously disagrees with the two manufacturers' claim that they had never changed the specification of the probes in the manner that the fall rate is affected.

The Sippican changed the coating of wire a few times in the past (LMS, personal communication, 2008). A major change occurred in 1996. The linear density of its wire in air became slightly smaller by this change than before. However, the weight of the wire in water, as well as other parts such as nose weight, after-body and probe spool, is kept unchanged (LMS, personal communication, 2008). TSK claims that it has never changed the specification since its start of production.

A key question is from when and how the intermanufacturer differences occurred. If both the companies did not change their probe design except the changes of wire coating by the Sippican, as the manufacturers recognize, the two companies' T-7 must have had some structural difference since the TSK started its manufacture. Another important point is that there is weight difference, which is obviously larger than the industrial tolerances of the manufacturers, for at least some of the recent probes.

Even if the difference is just caused by lot-to-lot variance, it means that the relative fall-rate difference between the two manufacturers is sometimes well excess of their $2 \%$ depth accuracy claims. We would therefore need to tolerate larger depth disagreement if we mix the profiles obtained by the two companies' probes.

There are more questions. The data of $\mathrm{H} 95$ were taken during years from 1987 through 1992 though they did not describe the dates of production nor the serial numbers of the individual probes they used. Many sea tests prior to H95 demonstrated systematic bias of the Sippican's original fallrate coefficients as aforementioned, and many articles supported H95 after the mid-1990s until Gouretski and Koltermann (2007). W08 implied that the original coefficients by the Sippican were more accurate for the XBT profiles in the 1970s than the H95 which gives 3.3\% larger depth than the former (see their Fig. 6d and h). This disagrees with the fact that multiple studies in the 1970s commonly demonstrated systematic negative depth bias of more than $2 \%$ by the original Sippican coefficients at $750 \mathrm{~m}$ depth (e.g., Flierl and Robinson, 1977; Federov et al., 1978). In addition, H95 showed that the TSK T-6 have marginally but systematically slower (by about $-1.3 \%$ ) fall rate than the T-7 and the Sippican T-4/T-6 (see their Fig. 10) while W08 showed that "shallow" probes dropped in the Northwest Pacific, which were supposed to be TSK T-6 in their study, had a few times larger negative depth bias during the same period (see their Fig. 6d): negative depth bias means that the true fall-rate is faster than H95 predicts.

Unfortunately, detail information about the manufacture of the XBT is hard to obtain because of the industrial secrets. Therefore, we can not tell if/how the probes manufactured decades ago and recent ones actually differ. However, some description could be made. For instance, the TSK has been checking the weight of every metal nose and a total probe 
unit. The linear-density of wire is also checked on a batch basis (TSK, personal communication, 2008). Its allowance for the total probe weight is $1 \mathrm{~g}$, in contrast to $5 \mathrm{~g}$ by LMS as aforementioned, but its routine check has been made only in air (i.e. not in water) and for weight.

According to the LMS, the company controls the weight of the nose to be $575 \pm 1 \mathrm{~g}$. The precision of weight of the wire for each probe is $\pm 1.5 \mathrm{~g}$, and wire samples are inspected for leaks during elongation and dereeling in simulated sea water. The dimensions of the nose and after-body are also checked to comply with tolerances specified per drawings. All components of the Sippican XBT except for the nose and wire are very close to neutrally buoyant.

In summary, the two manufacturers claim that they have kept their controls on weights and dimensions of various parts of the instrument. However, details and numerical criteria particularly for the latter are not opened, and it seems that those screenings have not been performed across the companies. Therefore, it is not clear whether the dimensional differences identified between the present LMS sample probes and the TSK samples (both for T-7 and T-5) were already existent at the start of the TSK manufacture or occurred later.

According to the TSK's present quality control, variance in the weight of nose (within its tolerance) is cancelled by adjusting the length of probe wire in air. However, it is not known if this cancellation is still valid in water. Even if the cancellation is perfect and the initial weight in water is kept constant, slight difference of weight may arise as the probe wire is unreeled. Also, the mass balance is different between the short-range probes (the T-4 and the T-6) and the mediumrange probes (the T-7 and the Deep Blue), even if their total weight is kept identical, because the probe spool is located behind the nose weight. The LMS production does not include such cancellation of weight (LMS, personal communication, 2010).

If we collect the full-wire-length data for every profile we take, we may be able to monitor the possible variation of wire length and hence the possible change in the mass balance of the probes. Unfortunately, this can not be achieved by the present acquisition systems by the TSK, which automatically terminate acquisition of data at the rated depths. Also, the canister wire, which is collectable, may be a good indicator of the change of the wire density. Because the linear density of wire is directly related to the $b$ coefficient of the fall-rate equation, it could help assessing the applicability of the accepted fall-rate equation.

\section{Concluding remarks}

It is clearly shown that the recent T-7 manufactured by the two companies have different structure and weight and that the fall-rate equation by $\mathrm{H} 95$ is biased for both of them. However, it is not clarified yet how $2 \%$ difference in total probe weight and various small structural differences could generate $3.5 \%$ difference in their fall rates. Also, it is not known when these differences occurred. The temperature dependency of the fall rate is existent but too small to explain the depth bias identified in the present analysis.

The authors do not think that the present fall-rate estimation should be reflected immediately in the past time series of ocean heat content because there is no proof that the recent probes and the old probes should have the identical fall rate. Similar investigation will need to be repeated regularly in the future in various parts of the world ocean to assess the lot-to-lot differences and/or effects of sea state and launching condition.

The T-7 manufactured by TSK and the Sippican had been believed to have an identical fall rate, but the truth is not. Similarly, Kizu et al. (2005a, b) showed that the Sippican T-5 and the TSK T-5 had different weight and fall rates though they had been considered identical. The users of XBT need to recognize that the two companies' products are often different. The T-6, though not investigated here, could be subject to similar inter-manufacturer differences because it consists of the same parts (except the inner design and weight of the nose weight) and the outer shape as the T-7 of individual manufacturers. Therefore, it is highly recommended that any data archive keeps the information of probe serial number as well as probe type and manufacturer as a metadata. Those set of information are vital whenever we try to review manufacture of specific probes and/or to correct depth error that could be found later.

The XBT was originally developed to enable profiling of temperature by fast-cruising military vessels. The instrument has been used for various and perhaps often more sensitive purposes than originally anticipated by the developers of the instrument. A $2 \%$ depth error could eliminate some important "observational facts" about decadal variability of the ocean, and it could present very different view of global warming (e.g., Wijffels et al., 2008; Carton and Santorelli, 2008). The users should know how much we can really expect on this convenient device, and the manufacturers should recognize how crucial the depth accuracy of their probes is for the climate studies.

\section{Appendix A}

The sales territories of the LMS and the TSK are given below (as of December 2010; LMS, personal communication, 2010). For countries not listed here, no agreement is made yet (TSK, personal communication, 2010). It should also be noted that this information may change in the future according to the companies' polity.

- LMS: Europe, North America, South America, Australia, New Zealand, India, Malaysia, Singapore, South Korea (military), Taiwan (military), Thailand (military). 
- TSK: Japan, China, South Korea (civilian), Taiwan (civilian), Thailand (civilian).

Acknowledgements. The authors sincerely thank Akira Kusaka at the Hokkaido National Fisheries Research Institute and all the crew involved in our sea test. We are also grateful to the Tsurumi Seiki Co. Ltd., and the Lockheed Martin Sippican Inc., for providing their probes and information. The major part of the probe investigation was made in the Shirakawa Factory of TSK. We appreciate Franco Reseghetti, Ann Gronell Thresher, Steve Rintoul, Tim Boyer, Dean Roemmich, and two anonymous reviewers for their various comments and help.

Edited by: S. Arnault

\section{References}

Anderson, E. R.: Expendable bathythermograph (XBT) accuracy studies - final report for period May 1971-December 1979, NOSC-TR-550, Naval Ocean Systems Center, San Diego, CA, USA, 212 pp., 1980.

Baker, D. J.: Ocean instruments and experiment design, in: Evolution of Physical Oceanography, edited by: Warren, B. A. and Wunsch, C., MIT Press, Cambridge, Mass., 396-433, 1981.

Barnett, T. P. and Bernstein, R. L.: Expendable measuring devices, in: Air-Sea Interaction: Instruments and Methods, edited by: Dobson, F., Hasse, L., and Davis, R., Plenum Press, 801 pp., 1980.

Biggs, D. C.: Nutrients, plankton, and productivity in a warm-core ring in the western Gulf of Mexico, J. Geophys. Res., 97(C2), 2143-2154, 1992.

Bindoff, N. L., Willebrand, J., Artale, V., Cazenave, A., Gregory, J., Gulev, S., Hanawa, K., Le Quèrè, C., Levitus, S., Nojiri, Y., Shum, C. K., Talley, L. D., and Unnikrishnan, A.: Observations: Oceanic Climate Change and Sea Level, in: Climate Change 2007: The Physical Science Basis. Contribution of Working Group I to the Fourth Assessment Report of the Intergovernmental Panel on Climate Change, edited by: Solomon, S., Qin, D., Manning, M., Chen, Z., Marquis, M., Averyt, K. B., Tignor, M., and Miller, H. L., Cambridge University Press, Cambridge, United Kingdom and New York, NY, USA, 2007.

Boyer, T. P., Antonov, J. I., Baranova, O. K., Garcia, H. E., Johnson, D. R., Locarnini, R. A., Mishonov, A. V., Seidov, D., Smolyar, I. V., and Zweng, M. M.: World Ocean Database 2009, edited by: Levitus, S., NOAA Atlas NESDIS 66, US Gov. Printing Office, Wash., D. C., DVDs, 216 pp., 2009.

Carton, J. A. and Santorelli, A.: Global decadal upper-ocean heat content as viewed in nine analyses, J. Climate, 21, 6015-6035, 2008.

Demeo, R. P.: The validity of expendable bathythermograph measurements, Transactions: Marine Temperature Measurement Symposium, 155-179, June 1969.

Emery, W. J. and Thomson, R. E.: Data analysis methods in physical oceanography, Second and revised edition, Elsevier, 638 pp., 2004.

Federov, K. N., Ginsburg, A. I., and Zatsepin, A. G.: Systematic differences in isotherm depths derived from XBT and CTD data, POLYMODE News, 50, 30 June 1978.
Flierl, G. R. and Robinson, A. R.: XBT measurements of thermal gradients in the MODE eddy, J. Phys. Oceanogr., 7, 300-302, 1977.

Francis, S. A. and Campbell, G. C.: A low cost expendable bathythermograph, Marine Sciences Instrumentation, vol. 3, Proc. 3rd National Marine Sciences Symposium, Miami, Florida, 21-23 April 1965.

Good, S.: Depth biases in XBT data diagnosed using bathymetry data, J. Atmos. Ocean. Tech., 28, 287-300, doi:10.1175/2010JTECHO773.1, 2011.

Gouretski, V.: Instrument-related temperature biases and their impact on estimation of the long-term ocean temperature, NOAA XBT Fall Rate Workshop, Miami, USA, 10-12 March 2008.

Gouretski, V. and Koltermann, K. P.: How much is the ocean really warming, Geophys. Res. Lett., 34, L01610, doi:10.1029/2006GL027834, 2007.

Gouretski, V. and Reseghetti, F.: On depth and temperature biases in bathythermograph data: development of a new correction scheme based on analysis of a global ocean database, Deep-Sea Res., 57(6), 812-833, 2010.

Green, A. W.: Bulk dynamics of the expendable bathythermograph (XBT), Deep-Sea Res., 31(4), 415-426, 1984.

Hallock, Z. R. and Teague, W. J.: The fall rate of the T-7, J. Atmos. Ocean. Tech., 9, 470-483, 1992.

Hanawa, K. and Yoritaka, H.: Detection of systematic errors in XBT data and their correction, J. Oceanogr. Soc. Japan, 43, 68-76, 1987.

Hanawa, K. and Yoshikawa, Y.: Reexamination of the depth error in XBT data, J. Atmos. Ocean. Tech., 8, 422-429, 1991.

Hanawa, K. and Yasuda, H.: New detection method for XBT depth error and relationship between the depth error and coefficients in the depth-time equation, J. Oceanogr., 43, 68-76, 1992.

Hanawa, K., Rual, P., Bailey, R., Sy, A., and Szabados, M.: Calculation of new depth equations for expendable bathythermographs using a temperature-error-free method (application to Sippican/TSK T-7, T-6 and T-4 XBTs), IOC Tech. S., UNESCO, 42, 47 pp., 1994.

Hanawa, K., Rual, P., Bailey, R., Sy, A., and Szabados, M.: A new depth-time equation for Sippican or TSK T-7, T-6 and T4 expendable bathythermograph (XBT), Deep-Sea Res., 42(8), 1423-1451, 1995.

Hannon, J.: New developments in expendable oceanographic sensors and data, acquisition systems, OCEANS 2000 MTS/IEEE Conference and Exhibition, 3, 1875-1881, 2000.

Heinmiller, R. H., Ebbesmeyer, C. C., Taft, B. A., Olson, T. B., and Nikitin, O. P.: Systematic errors in expendable bathythermograph (XBT) profiles, Deep-Sea Res., 30, 1185-1197, 1983.

Hottel Jr., H. C. M.: Expendable wire links, IEEE T. Commun., 20, 479-483, 1972.

Ishii, M. and Kimoto, M.: Reevaluation of historical ocean heat content variations with time-varying XBT and MBT depth bias corrections, J. Oceanogr., 65, 287-299, 2009.

Kizu, S., Itoh, S., and Watanabe, T.: Inter-manufacturer difference and temperature dependency of the fall-rate of T-5 expendable bathythermograph, J. Oceanogr., 61, 905-912, 2005 a.

Kizu, S., Yoritaka, H., and Hanawa, K.: A new fall-rate equation for T-5 expendable bathythermograph (XBT) by TSK, J. Oceanogr., 61, 115-121, 2005b.

Kizu, S., Onishi, H., Suga, T., Hanawa, K., Watanabe, T., and 
Iwamiya, H.: Evaluation of the fall rates of the present and developmental XCTDs, Deep-Sea Res., 55, 571-586, doi:10.1016/j.dsr.2007.12.011, 2008.

Little, A. D. Inc.: Experimental evaluation of expendable bathythermographs, ASW SONAR Tech. Rep., Report No. 4071165, 51 pp., 1965.

McPhaden, M. J., Busalacchi, A. J., Cheney, R., Donguy, J.R., Gage, K. S., Halpern, D., Ji, M., Julian, P., Meyers, G., Mitchun, G. T., Niiler, P. P., Picaut, J., Reynolds, R. W., Smith, N., and Takeuchi, K.: The tropical ocean-global atmosphere observing system: a decade of progress, J. Geophys. Res., 103(C7), 14169-14240, 1998.

Narayan, S. and Lilly, G. R.: On the accuracy of XBT temperature profiles, Deep-Sea Res., 40, 2105-2113, 1993.

Reseghetti, F., Borghini, M., and Manzella, G. M. R.: Factors affecting the quality of XBT data - results of analyses on profiles from the Western Mediterranean Sea, Ocean Sci., 3, 59-75, doi:10.5194/os-3-59-2007, 2007.

Reverdin, G., Marin, F., Bourlès, B., and L'Herminier, P.: XBT temperature errors during French research cruise (1999-2007), J. Atmos. Ocean. Tech., 26, 2462-2473, 2009.

Ridgway, K. R.: An application of a new depth correction formula to archived XBT data, Deep-Sea Res., 42(8), 1513-1519, 1994.

Roemmich, D. and Cornuelle, B.: Digitization and calibration of the expendable bathythermograph, Deep-Sea Res., 34(2), 299-307, 1987.

Seaver, G. A. and Kuleshov, S.: Experimental and analytical error of the expendable bathythermograph, J. Phys. Oceanogr., 12, 592600, 1982.

Shenoi, M. V.: New techniques in bathythermograph systems, Defence Sci. J., 26, 97-104, 1976.

Sippican Inc.: The effect of manufacturing tolerances, fluid density and viscosity variations on XBT depth accuracy, The Sippican Corporation internal document, R-752, 8 pp., 1976.

Singer, J. J.: On the error observed in electronically digitized T-7 data, J. Atmos. Ocean. Tech., 7, 603-611, 1990.
Smith, N. R., Harrison, D. E., Bailey, R., Alves, O., Delcroix, T., Hanawa, K., Keeley, B., Meyers, G., Molinari, B., and Roemmich, D.: The role of XBT sampling in the ocean thermal network, Proc. OCEANOBS 99, vol. 1, 26 pp., 1999.

Snowden, D., Baringer, M., and Goni, G.: Results for four fall rate experiments, NOAA XBT Fall Rate Workshop, Miami, USA, 10-12 March 2008.

Sprintall, J. and Meyers, G.: An optimal XBT sampling network for the Eastern Pacific Ocean, J. Geophys. Res., 96(C6), 1053910552, 1991.

Sy, A. and Wright, D.: XBT/XCTD standard test procedures for reliability and performance tests of expendable probes at sea, in: 3rd Session of JCOMM Ship-of-Opportunity Implementation Panel (SOOPIP-III), La Jolla, CA, USA, 8 pp., 28-31 March 2000.

Thadathil, R., Saran, A. K., Ghosh, A. K., and Muraleedharan, P. M.: An evaluation of XBT depth equations for the Indian Ocean, Deep-Sea Res., 45, 819-827, 1998.

Thadathil, R., Saran, A. K., Gopalakrishna, V. V., Vethamony, P., and Araligidad, N.: XBT fall rate in waters of extreme temperature; a case study in the Antarctic Ocean, J. Atmos. Ocean. Tech., 19, 391-396, 2002.

White, W. B. and Bernstein, R. L.: Design of an oceanographic network in the midlatitude North Pacific, J. Phys. Oceanogr., 9, 592-606, 1979.

Willis, J. K., Lyman, J. M., Johnson, G. C., and Gilson, J.: In situ data biases and recent ocean heat content variability, J. Atmos. Ocean. Tech., 26., 846-852, 2009.

Wijffels, S. E., Willis, J., Domingues, C. M., Barker, P., White, N. J., Gronell, A., Ridgway, K., and Church, J. A.: Changing expendable bathythermograph fall-rates and their impact on estimates of thermosteric sea level rise, J. Climate, 21, 5657-5672, 2008.

Wright, D. and Szabados, M.: Field Evaluation of Real-Time XBT Systems, Proc. OCEANS '89, 5, 1621-1626, 1989. 